\title{
Absceso hepático drenado a cavidad pleural
}

\author{
Hepatic abscess ruptured into the pleural cavity \\ Jorge Alberto Carrillo, Juan Mauricio Pardo • \\ BogotÁ, D.C. (Colombia)
}

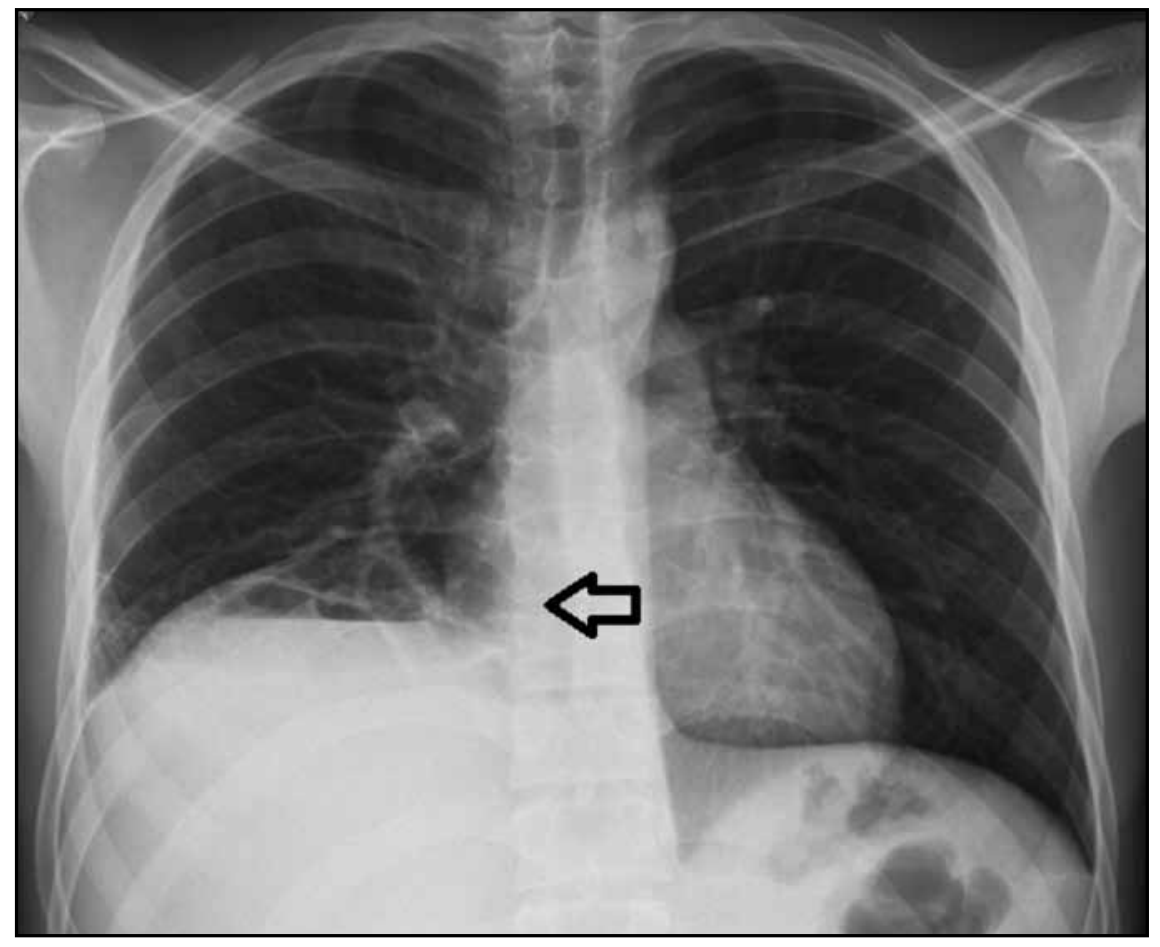

Figura A. Elevación del hemidiafragma derecho, con nivel hidroaéreo subfrénico, e imagen radiolucida basal derecha.

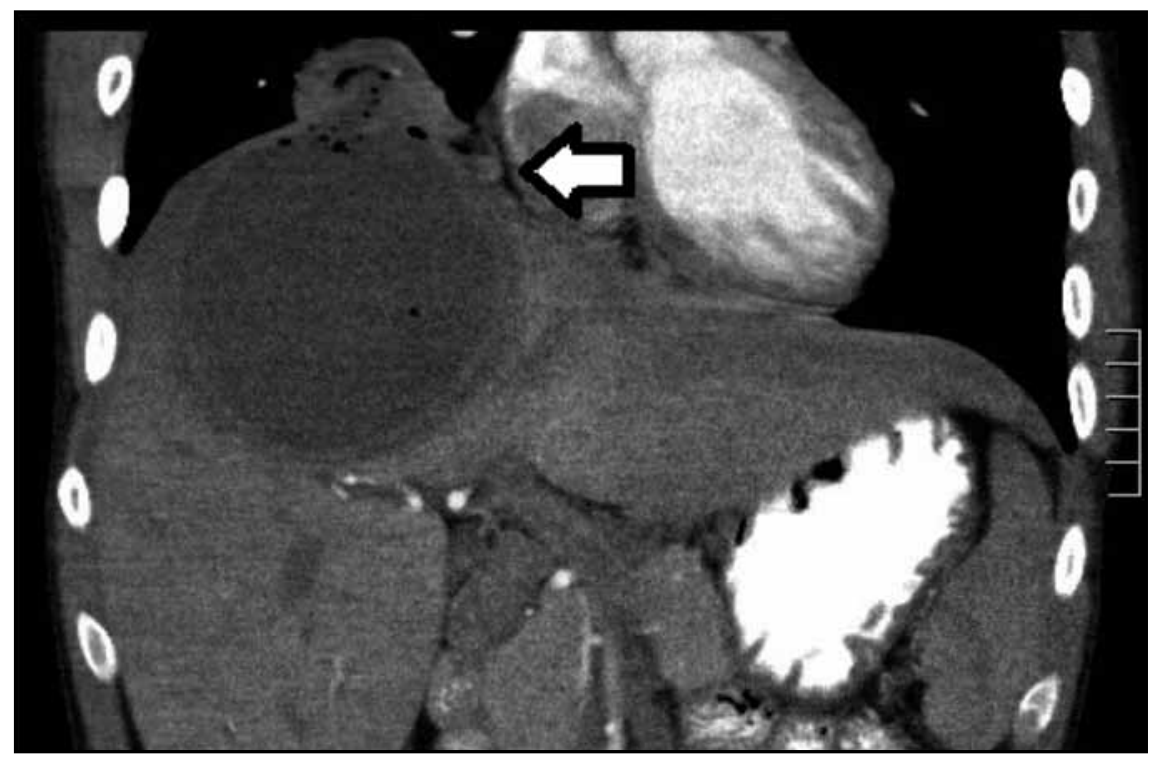

Figura B. Disrupción del hemidiafragma derecho, con drenaje a la cavidad pleural de colección hepática.
Paciente de 20 años, con absceso hepático mixto, que presenta como complicación empiema pleural (Figura A). Radiografía de tórax: elevación del hemidiafragma derecho con nivel hidroaéreo subfrénico y bandas de atelectasia basales. Figura B. Tomografía computarizada con disrupción del hemidiafragama derecho con drenaje a pleura de colección pleural). Se inicio manejo antibiótico con piperacilina-tazobactam y metronidazol, así como toracostomía cerrada y drenaje percutáneo de la colección hepática guiado por ultrasonido, con resolución del cuadro.

Los abscesos hepáticos pueden drenarse a pulmón hasta en $10 \%$ de los casos, siendo una de sus complicaciones más frecuentes de los mismos.

Dr. Jorge Alberto Carrillo: Profesor Universidad del Rosario, Radiólogo Hospital Universitario Mayor, Mederi; Dr. Juan Mauricio Pardo Oviedo: Internista - Intensivista, Profesor Universidad Rosario. Jefe de Educación Médica, Hospital Universitario Mayor, Mederi. Bogotá, D.C. (Colombia).

Correspondencia. Dr Juan Mauricio Pardo. E mail: Juan.pardo@urosario.edu.co

Recibido: 25/V/2011 Aceptado: 25/V/2011 